\title{
Prevention and Reduction of Complications in Women with Vulvar Cancer: Development of an Algorithm for Safer Multidisciplinary Care
}

\author{
Beate Senn',2, Andrea Kobleder'1, Silvia Raphaelis ${ }^{3}$, Michael D. Mueller4, \\ Beatrice Kammermann ${ }^{4}$, Kathryn White ${ }^{2}$, Manuela Eicher ${ }^{5}$ \\ ${ }^{1}$ Institute for Applied Nursing Sciences IPW-FHS, St. Gallen, Switzerland \\ ${ }^{2}$ Sydney Nursing School, The University of Sydney, Sydney, Australia \\ ${ }^{3}$ Department of Nursing Science, Vienna, Austria \\ ${ }^{4}$ Department of Obstetrics and Gynecology, Berne, Switzerland \\ ${ }^{5}$ School of Health Sciences, University of Applied Arts and Sciences Western Switzerland, Fribourg, Switzerland \\ Email: andrea.kobleder@fhsg.ch
}

Received 10 August 2015; accepted 1 September 2015; published 4 September 2015

Copyright (C) 2015 by authors and Scientific Research Publishing Inc.

This work is licensed under the Creative Commons Attribution International License (CC BY).

http://creativecommons.org/licenses/by/4.0/

(c) (i) Open Access

\begin{abstract}
Purpose: Women who are surgically treated for vulvar cancer often have complications leading to substantial patient morbidity. Post-surgical complications could be minimized by the identification of pre-surgical risks for complications and by planned post-surgical interventions. Therefore, the aim of this study was to develop a clinical care algorithm for vulvar cancer to assess risk for complications and prevent and control post-surgical complications. Methods: Key elements of the algorithm were identified via a literature review, structured chart review, a survey of care team members and interviews with stakeholders including healthcare team, patients and their family. Results: An algorithm for the management of wound and psychosocial complications was developed, based on internal and external evidence and was vetted by expert reviewers. Conclusion: Describing the process and defining the roles of health care professionals contributes to purposeful, systematic prevention and treatment of post-surgical complications. The care algorithm provides structured reference points for healthcare professionals with regard to multidisciplinary post-surgical management of vulvar cancer patients.
\end{abstract}

\section{Keywords}

Vulvar Cancer, Post-Surgical Complications, Care Algorithm, Health Care Professionals

How to cite this paper: Senn, B., Kobleder, A., Raphaelis, S., Mueller, M.D., Kammermann, B., White, K. and Eicher, M. (2015) Prevention and Reduction of Complications in Women with Vulvar Cancer: Development of an Algorithm for Safer Multidisciplinary Care. Journal of Cancer Therapy, 6, 821-832. http://dx.doi.org/10.4236/jct.2015.610090 


\section{Introduction}

Vulvar cancer is rare and accounts for 3\% - 5\% of female genital cancers, affecting approximately 27,000 women globally each year [1]. This translates to 1 - 7 cases per 100,000 European women per year [2]. An estimated 4490 new cases and 950 deaths from vulvar cancer occurred in the United States in 2012 [3]. Most of these cases are squamous cell carcinomas (85\% to 90\%), while the remaining includes other histologic types like adenocarcinoma, melanoma and Bartholin's gland cancers also occur. Like other cancers, vulvar cancer is staged on a scale from 0 - 4 based on criteria from the Fédération Internationale de Gynécologie et Obstétrique (FIGO) and the American Joint Committee on Cancer (AJCC) [4].

Vulvar cancer increases with age, the mean age being 72 years [2]. Approximately $30 \%-40 \%$ of patients are preceded by vulvar intraepithelial neoplasia (VIN) [5]. Other risk factors for vulvar cancer include Human Papilloma Virus (HPV) infection, other anogenital intraepithelial neoplasia or carcinoma, syphilis, herpes genitalis, Acquired Immunodeficiency Syndrome (AIDS), smoking, lichen sclerosis, and squamous cell hyperplasia [6] [7].

Standard therapy for vulvar cancer is surgery [8]. Depending on disease stage and lymph node involvement, this may involve different surgical methods such as wide local excision, partial or radical vulvectomy and inguinofemoral lymph node dissection [8] [9]. Further, (neo-) adjuvant chemotherapy and radiation therapy may also be indicated based on tumor staging and individual patient factors [10]. Surgical reconstruction of the vulva may improve morbidity and quality of life after treatment [11]. Recovery from minor surgical procedures involving slight tissue damage generally occurs within three weeks provided good circulation and primary wound healing [12]. However, even small excisions are susceptible to post-surgical complications. More involved, major vulvar cancer surgery requires longer recovery times and post-surgical complications can often delay wound healing [13]. Adoption of surgical modifications have helped reduce post-operative morbidity in women with vulvar neoplasia [14] and surgical therapy for women with vulvar cancer has improved substantially in the last decades yet multiple complications are still common [15]. These present challenges for nurses and other clinicians providing post-surgical care for these patients.

While guidelines for prevention and treatment of vulvar cancer have been developed to meet some of these challenges there is no evidence-based guideline (or decision-making aid) for prevention and treatment of postsurgical complications [16] [17]. Therefore, nurses in the gynecology ward of the University Hospital of Berne (Switzerland) initiated a project to develop a clinical care algorithm to improve the quality of pre- and post-surgical care for women with surgically-treated vulvar cancer.

\section{Methods}

Design: A 5-stage mixed-methods process was utilized to develop the final clinical algorithm (Figure 1). To identify key elements of the clinical algorithms, data were collected through several sources including: literature

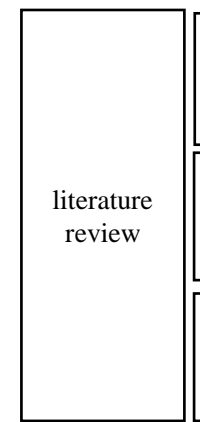

(a)

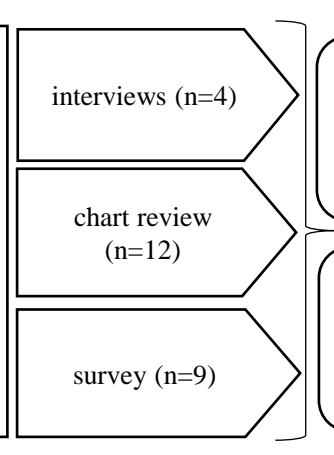

(b)

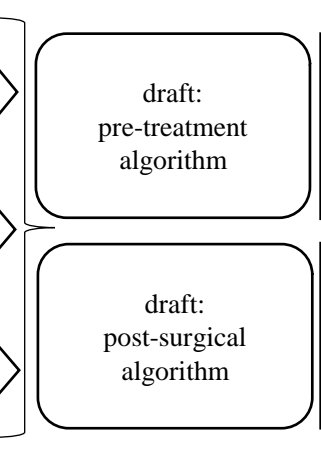

(c)

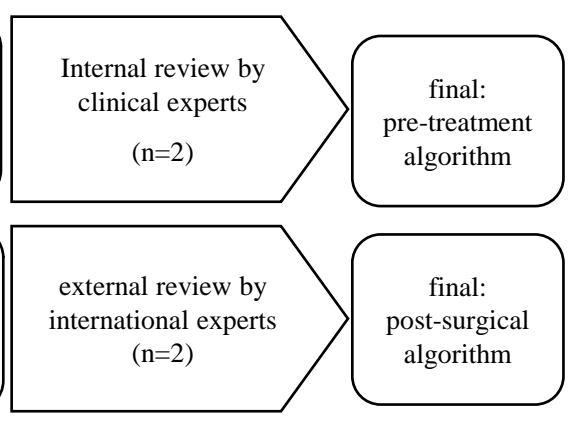

(d)

(e)

Figure 1. Schematic depicting the design of the algorithm development process. (a) A literature review identified risk factors for post-surgical complication as well as most frequently observed complications; (b) A situation analysis included semi-structured interviews, in parallel with structured chart review, and survey of care team members; (c) Drafted clinical algorithms were developed and underwent expert internal and external review (d) to produce the final algorithm guiding clinical care of women undergoing surgical treatment of vulvar cancer (e). 
review and through a data situation consisting of structured chart review, a survey of implicated care team members, and semi-structured interviews of stakeholders. Following synthesis of the analysis from the different data streams, a draft clinical algorithm was developed. Subsequently the algorithm underwent internal and external expert review to produce a final product.

Sample: A purposeful sampling was utilized for this project (Figure 1(b)). Semi-structured interviews were conducted with two patients, one gynecologist and one wound specialist nurse to explore experiences and issues related to post-surgical care of vulvar cancer. Medical records for the structured chart review of all hospitalized cases of surgically-treated vulvar cancer over the course of one year (2006, January $1^{\text {st }}-2006$, December $31^{\text {st }}$ ) were analyzed. Those cases that had diagnostic excisions at the vulva and were hospitalized and got surgically treated due to other diagnosis were excluded from the analysis. The survey was conducted among experienced nurses from the gynecological wards of the University Hospital in Berne.

Instrumentation: All investigator-developed questionnaires and interview guides were literature based and pre-tested with three or more persons [18]. The semi-structured interview guide, structured medical record data extraction form, and survey are provided in the supplemental materials.

Procedures: The project was part of an internal quality management program at the University Hospital of Berne and received approval from the clinic management. According to national law a submission of internal quality management programs at the responsible ethics committee is not required. Nurses and physicians informed all eligible participants about the project and all participants provided written informed consent prior to the initiation of study-related procedures and data collection. Nurses participating in the questionnaire survey received a project package containing a study description, informed consent form, and a questionnaire to complete. To ensure confidentiality, nurses were asked to return the signed consent form and completed survey questionnaire in a separate pre-addressed stamped envelope. Participants who did not respond were considered as non-responders.

The components of the algorithm were developed on the basis of available evidence from the literature and expertise (including qualitative data collected from expert clinicians and patients). The draft of the evidencebased algorithm was developed in three steps as previously described [19]. First, literature review was conducted by a project team at the University Hospital in Berne (Figure 1(a)) on factors associated with post-surgical wound complications in vulvar cancer patients. PubMed, CINAHL, ERIC, and Cochrane Library databases we utilized and results analyzed by three nurses with expertise in gynecological cancer care [20]. The literature research was replicated during the preparation of this manuscript to include literature published between August 2013-January 2014. This review was used to identify the initial key components of the clinical algorithm.

Second, an analysis of wound complications was conducted using semi-structured interviews (Figure 1(b)) to explore the experiences during the post-operative phase of vulvar cancer treatment. In parallel, retrospective medical records data were collected for a one-year period from on all surgically-treated women with vulvar neoplasia and a survey was conducted with experienced nurses from the gynecological wards of the University Hospital in Berne. All data were collected by the first author (BS). Results of the literature analysis (Table 1), the interviews (Table 2) and the patient records (Table 3) built the basis for the development of the algorithm, including a pre-operative and a post-operative phase.

Third, the data streams were combined to produce a resulting algorithm draft (Figure 1(c)). Each step was discussed and reviewed by two experts in clinical practice from the University Hospital in Berne. The pre-final version underwent a critical review by two international clinical experts (Figure 1(d)) [21].

\section{Analysis}

The results of the literature review was analyzed and synthesized by three investigators (BS, BK, ME). Semistructured interviews assessing post-surgical wound complications were recorded and transcribed, using pseudonyms [22]. The transcripts were analyzed according to the principles of content analysis with paraphrasing, generalization and reduction [23]. Data extraction from the retrospective medical record chart review were analyzed, employing descriptive statistics [24]. The survey data were collated and responses grouped and themed to identify frequent, recurrent and interrelated themes.

\section{Results}

The prior conducted literature review (Table 1) built the basis for the steps B-E (Figure 1). In total, interviews 
Table 1. Step A of the algorithm development process: Search terms and identified articles by literature review.

\begin{tabular}{|c|c|}
\hline Search terms & Literature identified \\
\hline $\begin{array}{l}\text { "wound healing", "wound management", "wound } \\
\text { treatment", "surgical wounds", "vulvar intraepithelial } \\
\text { neoplasia", "vulvar cancer" }\end{array}$ & $\begin{array}{l}\text { Artioukh et al., 2007; Bostellar et al., 2006; Beesley et al., 2007; Hullu de et al., } \\
\text { 2006; Gaarenstroom et al., 2003; Gottrup et al., 2005; Leminem et al., 2000; } \\
\text { Luesley et al., 2006; Maier et al., 2011; McNees et al., 2006; Rouzier et al., } \\
2003\end{array}$ \\
\hline $\begin{array}{l}\text { "surgical wounds", "sexu*”, "body image”, "vulvar } \\
\text { intraepithelial neoplasia”, "vulvar cancer", } \\
\text { "psychosocial” }\end{array}$ & $\begin{array}{l}\text { Andersen et al., 1983; Green et al., 2000; Janda et al., 2004; Jefferies et al., } \\
\text { 2011; Likes et al., 2008; Mitchell et al., 2007; Senn et al., 2010; Senn et al., } \\
\text { 2013; Thuesen et al. } 1992\end{array}$ \\
\hline $\begin{array}{l}\text { "surgical wounds", "wound healing”, "smoking”, } \\
\text { "alcohol consumption”, "nutrition”, "obesity”" }\end{array}$ & $\begin{array}{l}\text { Grønkjær et al., 2014; Nickelsen et al., 2005; Oppedal et al.,2012; Sørensen et } \\
\text { al., 2013; Thomsen } \text { et al., } 2010\end{array}$ \\
\hline
\end{tabular}

Table 2. Step B of the algorithm development process: Semi-structured interviews with stakeholders and consistent themes.

\begin{tabular}{cll}
\hline Interviews with stakeholders & & \multicolumn{1}{c}{ Consistent themes } \\
& & \\
Gynecologist & Pharmacological therapy \\
$\mathrm{n}=1$ & - & Wound assessment, treatment and nutrition \\
& - & Multidisciplinary collaboration \\
& - & Responsibilities in wound care \\
& & \\
Patients & - & Information about wound care, treatment and nutrition \\
$\mathrm{n}=2$ & - & Involvement of family and caregivers \\
& - & Multidisciplinary collaboration \\
$\mathrm{n}=1$ & - & Information given to the patient regarding wound treatment, healing and nutrition \\
Wound specialist nurse & - & Multidisciplinary collaboration \\
& & Responsibilities in wound care \\
\hline
\end{tabular}

Table 3. Step B of the algorithm development process: Items and the results of chart review $(n=12)$.

\begin{tabular}{|c|c|}
\hline Items abstracted via chart review & No. $(\%)$ \\
\hline \multicolumn{2}{|l|}{ Tumor staging } \\
\hline I & $4(33.3 \%)$ \\
\hline II & $5(41.7 \%)$ \\
\hline III & $3(25 \%)$ \\
\hline IV & $0(0 \%)$ \\
\hline Involvement of lymph nodes & $10(83.3 \%)$ \\
\hline Nutritional status $\mathrm{BMI} \geq 25$ & $8(66.6 \%)$ \\
\hline Involvement nutritionist & $4(33.4 \%)$ \\
\hline Involvement wound specialist & $1(8.3 \%)$ \\
\hline Wound documentation & $12(100 \%)$ \\
\hline Checklist wound documentation & $4(33.3 \%)$ \\
\hline Information about wound status given to patient & $9(75 \%)$ \\
\hline Patient education & $8(66.7 \%)$ \\
\hline Wound infections & $9(75 \%)$ \\
\hline Wound healing after hospital stay & $7(58.3 \%)$ \\
\hline Age in years; median (range) & $68.5(46-75)$ \\
\hline Lengths of hospital stay in days, median (range) & $12(4-50)$ \\
\hline
\end{tabular}


were conducted with two patients, one gynecologist and one wound specialist nurse (Table 2). The review of clinical cases presented over the year 200616 identified cases of patients with vulvar cancer, of which 12 (75\%) were surgically treated and included in the analysis (Table 3). Eleven experienced nurses were sent the survey questionnaire, 9 (81\%) of whom returned completed surveys (Table 4). Consistent themes across the methods were: 1) pre-surgical patient information, 2) multidisciplinary collaboration, 3) wound documentation and 4) education of patients and their families.

Literature review and qualitative data collection identify risk factors for post-surgical complications:

Results from the literature review show that like other surgery patients, women with vulvar neoplasia have patient-related risk factors possibly leading to post-surgical complications. They can be wound-related or caused by psychosocial factors.

Assessing these risk factors is essential for delivering individual information to patients. In connection with post-surgical wound complications smoking is a substantial factor that can lead to delayed wound healing [25]. Sørensen et al. reported that even perioperative cessation significantly reduces surgical side infections [26]. Furthermore, there is evidence, that counselling and nicotine replacement therapy can have an effect on postsurgical complications [27]. Alcohol consumption is another factor associated with an increased post-surgical wound complication rate. Pre-surgical alcohol cessation interventions can significantly decrease wound complications [28]. Additionally, nurses and clinicians must assess patient nutritional status. Obesity as well as malnutrition can negatively affect post-surgical wound healing [29]. In particular, patients with cancer are likely to be taking medications contraindicated for effective wound healing [30] [31]. Thus, medication review is essential and regimens may need to be adapted with regard to elective surgery. In addition to wound-related complications, the assessment of risk factors for psychosocial complications is an essential part of caring for patients with vulvar neoplasia. These risk factors include anxiety, depression as well as problems concerning sexuality and body image [32].

Table 4. Step B of the algorithm development process: Survey with nurses about their wound care practice during the last year $(n=11$, participant rate $n=9,81.8 \%)$

\begin{tabular}{|c|c|}
\hline Characteristics & No. (\%) \\
\hline \multicolumn{2}{|c|}{ Good collaboration between physicians and nurses } \\
\hline Majoritarian & $5(55.6 \%)$ \\
\hline Yes & $3(33.3 \%)$ \\
\hline Only partially & $2(22.2 \%)$ \\
\hline No & $0(0 \%)$ \\
\hline \multicolumn{2}{|l|}{ Characteristics ( multiple answers possible) } \\
\hline \multicolumn{2}{|c|}{ Topics for trainings, which would improve nursing quality } \\
\hline Other & $7(58.3 \%)$ \\
\hline Patient information & $8(66.7 \%)$ \\
\hline Assessment/treatment wound pain & $6(50 \%)$ \\
\hline Documentation of wound size & $4(33.3 \%)$ \\
\hline Assessment of the peri-wound area & $4(33.3 \%)$ \\
\hline Wound infection signs & $3(25 \%)$ \\
\hline Wound assessment & $6(50 \%)$ \\
\hline Handling wound documentation & $4(33.3 \%)$ \\
\hline \multicolumn{2}{|c|}{ Postsurgical problems discussed with patients } \\
\hline Odor development of the wound & $6(50 \%)$ \\
\hline Wound/skin damage & $8(67 \%)$ \\
\hline Lymphedema & $5(42 \%)$ \\
\hline Bowel dysfunctions & $5(41.7 \%)$ \\
\hline Bladder dysfunctions & $6(50 \%)$ \\
\hline Sexuality & $5(41.7 \%)$ \\
\hline Shame & $4(33.3 \%)$ \\
\hline Body image disturbances & $9(75 \%)$ \\
\hline Pain & $8(66.7 \%)$ \\
\hline Reduced Mobility & $9(75 \%)$ \\
\hline Hopelessness/grief & $6(50 \%)$ \\
\hline Crisis & $6(50 \%)$ \\
\hline Fear & $7(58.3 \%)$ \\
\hline
\end{tabular}


Complications are defined as medical problems occurring during a disease or after treatment and are diagnosed by clinicians according to clinical parameters [4]. Among post-surgical complications, infection is a major problem. The main diagnostic criteria for wound infection include fever, leukocytosis, positive blood cultures, and serous or purulent wound exudate [33]. Available evidence on post-vulvar-surgery complications primarily focuses on physical and psychosocial effects [32]. Among physical complications, wound dehiscence, wound infections, venous thrombosis, pulmonary embolism, pressure ulcers, introitale stenosis, urine incontinence/dysuria, rectocele, fecal incontinence, inguinal seroma, lymphedema, hernia, pain, scars, adhesions, and eschar development are possible negative sequelae. Lower extremity lymphedema (30\% to $70 \%$ ), wound dehiscence and infection (20\% to 40\%) are reported most frequently post-surgical treatment in women with vulvar cancer [34].

In a cross-sectional US study of 53 women with surgically treated vulvar cancer, lower-limb lymphedema was the most common complication and was experienced by $36 \%$ of the women [35]. Wound dehiscence and wound infection were reported in up to $85 \%$ of patients after radical vulvectomy and lymphadenectomy [36]. In a retrospective observational study of 101 patients following modified, radical vulvectomy and bilateral lymphadenectomy, Gaarenstroom and colleagues reported 9\% - 17\% of women experienced wound dehiscence, $9 \%$ - 39\% suffered infection and $40 \%$ developed lymph cysts [13].

Less radical treatment that disfigures the genitals to a lesser degree, results in less frequent post-surgical wound complications [37]. A retrospective observational study examining complications following vulvectomy in 149 patients, Leminen et al. (2000) found that modified surgical techniques decreased dehiscence rates by $27 \%$ and infection by $28 \%$. Psychosocial complications have been addressed in some studies and mainly examine the effect on sexual function [38] [39]. A retrospective study in the US compared pre-operative and post-operative sexual dysfunction along with scoring of body image among vulvar cancer patients. This survey of 41 women revealed significant sexual dysfunction $(\mathrm{p}<0.01)$ and disturbed body image $(\mathrm{p}<0.004)$ three months after surgical treatment [38].

Notably, relatively few studies focus on psychosocial outcomes such as body image, partner relationships, and quality of life [6] [40]. These women also experience distressing symptoms resulting from sitting, carrying out daily activities and suture/skin rupture [41].

The literature review indicates a high post-surgical complication rate among women with vulvar cancer. Therefore, nurses and other clinicians need to develop further measures to assess and manage surgery-related problems and to deal with emotional concerns of affected women. This requires taking into account the decreasing post-surgery length of stay which reduces time for information and education concerning symptom assessment and management [42]. Women with vulvar neoplasia are usually discharged before their surgical wound has healed. Follow-up visits are habitually scheduled every three months during the first three years to detect recurrent cancer and to prevent predictable complications [43]. Women and their families require support to assess and to manage symptoms that may cause complications [34].

From these data streams, key elements of the clinical algorithm emerged (Figure 2, Figure 3). The algorithm focuses on the pre-operative (Figure 2) and post-operative treatment phase (Figure 3). It describes the involvement of various disciplines, steps to prevent and control post-surgical complications as well as information and counseling for patients and families. In the pre-operative flowchart assessment/treatment of smoking habits, alcohol consumption, nutritional status/body mass index, co-morbidities and current medication potentially contraindicated for wound healing are included.

Psychosocial concerns like anxiety/depression, body image, and sexuality should also be assessed. The patient should be given information at an appropriate literacy level and individualized education concerning pre-surgical and post-surgical procedures. If indicated, information, counseling/support, a wound management plan or referral to specialists should be provided by a nurse.

The post-operative flowchart (Figure 3) includes patient information, wound and supportive care needs assessment completed by a nurse according to local practice guidelines. In case of existing wound complication signs, the nurse will develop, apply and adapt the multidisciplinary wound management plan and include a wound specialist, dermatologist, and physician as necessary. Personalized oral/written information, counseling and support should be provided to patients according to individual needs (e.g. mobility, underwear, vulva care, selection of wound treatment, difficulties passing urine and during bowel movements). Additionally, such information and education regarding self-care should be shared with families and caregivers as needed. At the time of discharge, the patient should receive oral/written information and education regarding at-home wound management and other supportive care needs. 
Pre-operative assessment provided by nurses/physicians

- Smoking habits

- Alcohol Consumption

- Nutritional Status/BMI

- Co-Morbidities

- Current medication potentially contraindicated for wound healing

Patient enters hospital for vulvar surgery
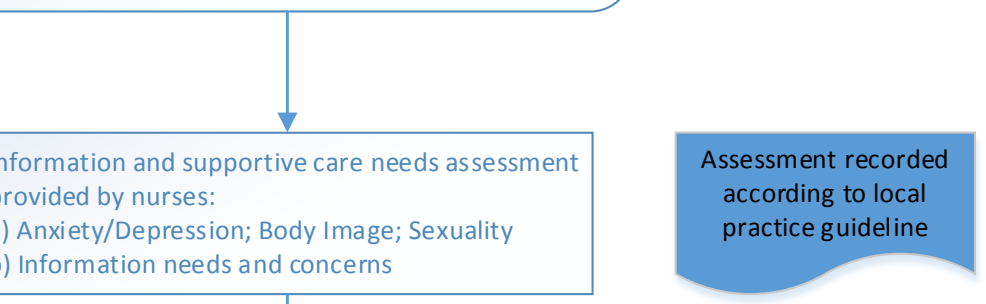
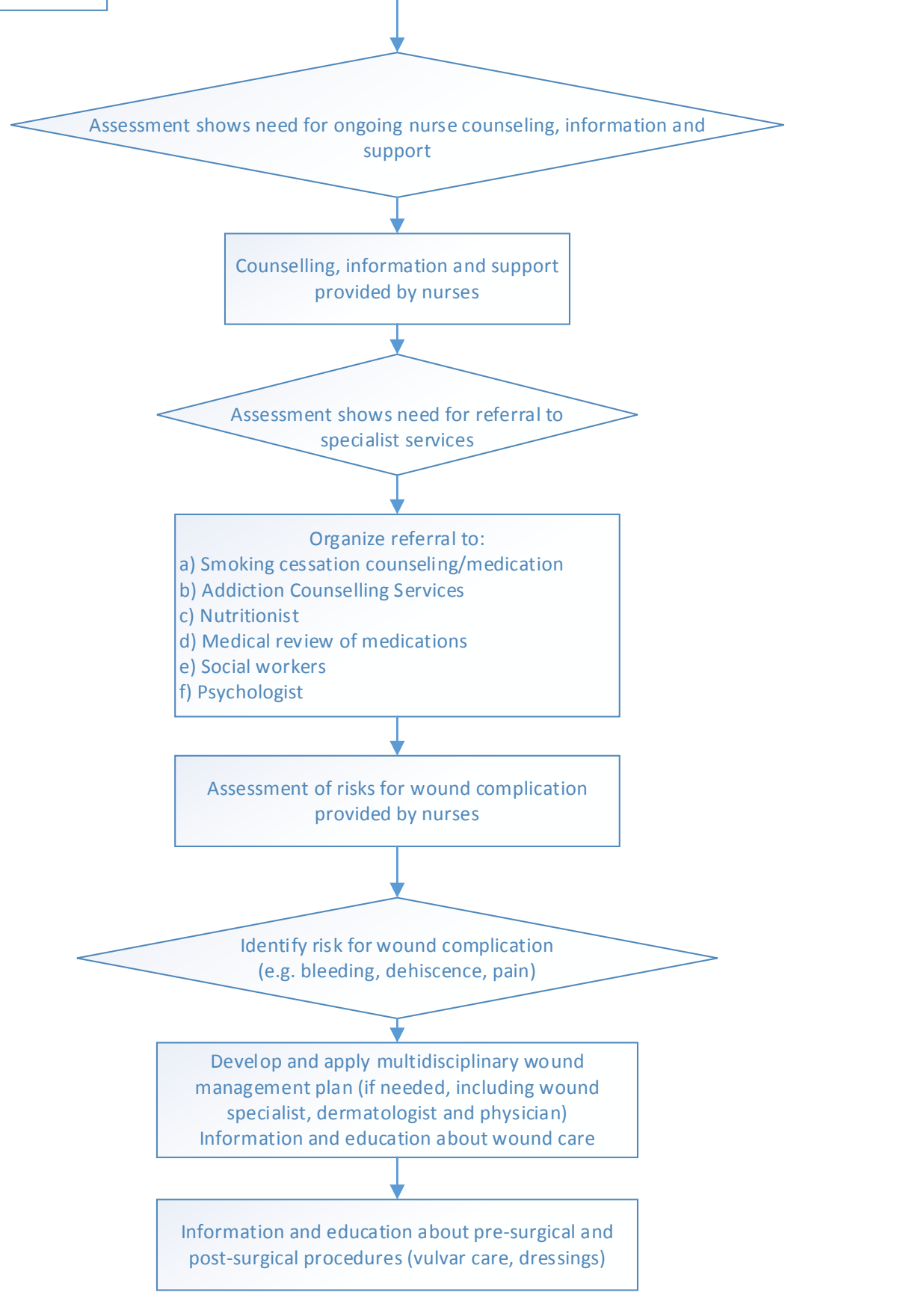

Figure 2. Pre-surgical flowchart for multidisciplinary wound management in women with surgically treated vulvar cancer. 


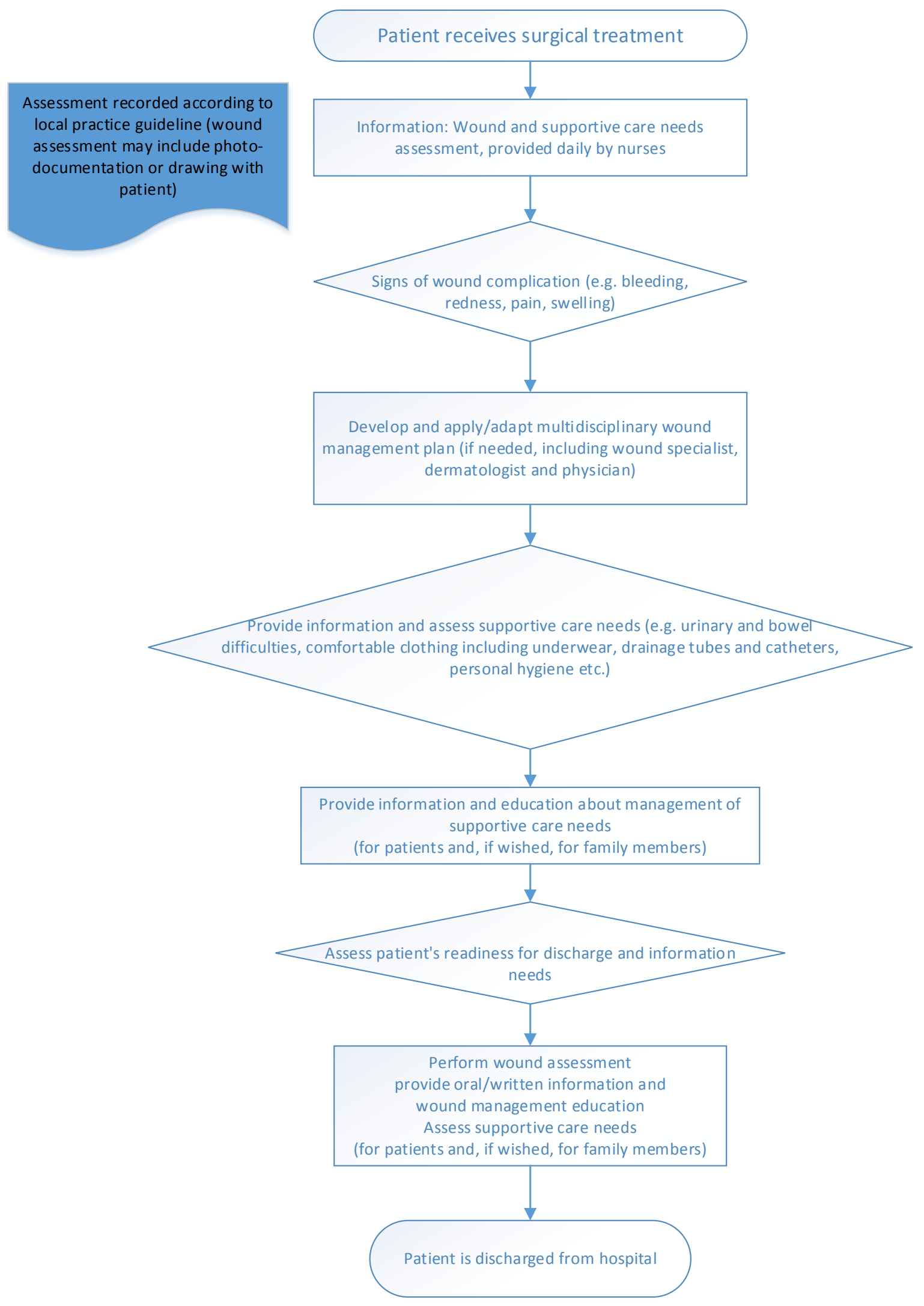

Figure 3. Post-surgical flowchart for multidisciplinary wound management in women with surgically treated vulvar cancer. 


\section{Discussion}

In this article we present the process and outcome of a structured process for developing a clinical algorithm for assessing risks for complications and to prevent and control post-surgical complications in women undergoing surgical treatment of vulvar cancer. This newly developed algorithm provides a framework guiding systematic, multidisciplinary management of these women and address the needs of their families. As suggested in the literature, early in the treatment process a systematic assessment of factors influencing wound healing, e.g. smoking habits, alcohol consumption, inadequate nutritional status, adiposity/obesity and medication were incorporated in the flowchart [26]-[30]. Standardized assessment of these factors provides the basis for the ensuing multidisciplinary wound management plan. Further, iterative, standardized assessment delivers an empirical basis to evaluate treatment efficacy [44]. In addition, we defined specific tasks and the timing of these interventions for members of the multidisciplinary team including physicians, nutritionists, social workers, psychologists, and wound specialists. Essential elements of a state-of-the-art nursing interventions were added to complement current clinical practice [19]. These include: consistent written information/counseling for patients and their family, photo documentation, assessing co-morbidities and addressing psychosocial concerns when patients express the need for supportive care [45] [46]. The algorithm was developed with the intent that it would provide structure to the care of these patients and would promote continuity during assessment and management of complications and psychosocial issues.

\section{Limitations}

Vulvar cancer is a rare form of cancer that typically develops slowly over the course of several years [4]. This is likely a reason for the limited evidence base on pre-surgical and post-surgical care among these patients. Indeed the literature review revealed a limited number of available studies [13] [35] [36] [38] [47]-[49]. Further only a few qualitative studies have examined difficulties with daily activities and problems with passing urine and bowel movements in this patient population [40] [50] [51]. Considering the frequency of post-surgical complications and intense need for quality improvement for this patient group, a pragmatic approach was chosen. We conducted a literature review, interviews with a limited number of patients/clinicians, a survey and analyzed medical records to develop an algorithm on the basis of the best available evidence. This process is limited by the lack of available data thus providing a modest evidence grade of D/level 2 - 3 (include e.g. expert opinion, non-analytic studies, case/cohort studies). However, it is our belief that this process is a fundamental first step that may serve as the basis for further development for care of these patients [52].

\section{Conclusion}

Despite the limited available evidence, this algorithm yields a suggested "best practice" to prevent and control post-surgical complications. It has been implemented as standard practice at the University Hospital in Berne involving patient education along with iterative individual feedback/instruction to improve the quality of care in women after hemivulvectomy, vulvectomy and exenterations [53]. In patients following skinning vulvectomy or local wide excision, the algorithm is implemented at the initial signs of post-surgical complication. This algorithm allows the evaluation of defined patient outcomes. The feasibility and utility for evaluation patient outcomes is presently ongoing. Furthermore, the algorithm is part of a nursing-led counseling intervention to reduce the number of post-surgical symptoms in women with vulvar neoplasia within the framework of an ongoing randomized controlled trial "WOMAN-PRO II" (ClinicalTrials. Gov ID: NCT01986725) [32]. Within the study the algorithm is going to be validated. Notably, additional research examining the associations and causal links between the critical factors identified as part of this algorithm development process and wound healing is needed. Communication is a key component of effective multidisciplinary care and future modification of this care pathway should include ambulatory follow-up visits and address ongoing, bi-directional communication with primary care providers. Additionally, programs to improve self-care and symptom management in this patient population are required. These could take the form of patient information booklets written at an appropriate health literacy or other modes for therapeutic education interventions. In summary, the clinical algorithms delineated here provide a framework guiding patient-centered, multidisciplinary care that can be used to guide both clinical management and research into this area. 


\section{References}

[1] Schuurman, M.S., van den Einden, L.C.G., Massuger, L.F.A.G., Kiemeney, L.A., van der Aa, M.A. and de Hullu, J.A. (2013) Trends in Incidence and Survival of Dutch Women with Vulvar Squamous Cell Carcinoma. European Journal of Cancer, 49, 3872-3880. http://dx.doi.org/10.1016/j.ejca.2013.08.003

[2] Dittmer, C., Katalinic, A., Mundhenke, C., Thill, M. and Fischer, D. (2011) Epidemiology of Vulvar and Vaginal Cancer in Germany. Archives of Gynecology and Obstetrics, 284, 169-174. http://dx.doi.org/10.1007/s00404-011-1850-9

[3] American Cancer Society (2012) Cancer Facts \& Figures-2012. http://pressroom.cancer.org/download/2012+Cancer+Facts+\%26+Figures.pdf

[4] National Cancer Institute (2013) Vulvar Cancer Treatment-For Health Professionals. Stage Information for Vulvar Cancer. http://www.cancer.gov/types/vulvar/hp/vulvar-treatment-pdq\#section/_16

[5] McFadden, K.M., Sharp, L. and Cruickshank, M.E. (2009) The Prospective Management of Women with Newly Diagnosed Vulval Intraepithelial Neoplasia: Clinical Outcome and Quality of Life. Journal of Obstetrics and Gynaecology, 29, 749-753. http://dx.doi.org/10.3109/01443610903191285

[6] Jefferies, H. and Clifford, C. (2011) A Literature Review of the Impact of a Diagnosis of Cancer of the Vulva and Surgical Treatment. Journal of Clinical Nursing, 20, 3128-3142. http://dx.doi.org/10.1111/j.1365-2702.2011.03728.x

[7] van de Nieuwenhof, H.P., Massuger, L.F.A.G., van der Avoort, I.A.M., Bekkers, R.L.M., Casparie, M. and Abma, W. (2009) Vulvar Squamous Cell Carcinoma Development after Diagnosis of VIN Increases with Age. European Journal of Cancer, 45, 851-856. http://dx.doi.org/10.1016/j.ejca.2008.11.037

[8] National Cancer Institute (2013) Vulvar Cancer Treatment-For Health Professionals. Cellular Classification of Vulvar Cancer. http://www.cancer.gov/types/vulvar/hp/vulvar-treatment-pdq\#link/stoc_h2_1

[9] Lai, K.W. and Mercurio, M.G. (2010) Medical and Surgical Approaches to Vulvar Intraepithelial Neoplasia. Dermatologic Therapy, 23, 477-484. http://dx.doi.org/10.1111/j.1529-8019.2010.01351.x

[10] Reade, C.J., Eiriksson, L.R. and Mackay, H. (2014) Systemic Therapy in Squamous Cell Carcinoma of the Vulva: Current Status and Future Directions. Gynecologic Oncology, 132, 780-789. http://dx.doi.org/10.1016/j.ygyno.2013.11.025

[11] Höckel, M. and Dornhöfer, N. (2008) Vulvovaginal Reconstruction for Neoplastic Disease. The Lancet Oncology, 9, 559-568. http://dx.doi.org/10.1016/S1470-2045(08)70147-5

[12] Bostelaar, R. (2006) Wundmanagement in der Klinik. Ein Ratgeber zum Umgang mit chronischen Wunden. Schlüter (Schlütersche Pflege), Hannover. http://deposit.ddb.de/cgi-bin/dokserv?id=2756623\&prov=M\&dok_var=1\&dok_ext=htm

[13] Gaarenstroom, K.N., Kenter, G.G., Trimbos, J.B., Agous, I., Amant, F., Peters, A.A.W. and Vergote, I. (2003) Postoperative Complications after Vulvectomy and Inguinofemoral Lymphadenectomy Using Separate Groin Incisions. International Journal of Gynecological Cancer, 13, 522-527. http://dx.doi.org/10.1046/j.1525-1438.2003.13304.X

[14] Gray, H.J. (2010) Advances in Vulvar and Vaginal Cancer Treatment. Gynecologic Oncology, 118, 3-5. http://dx.doi.org/10.1016/j.ygyno.2010.04.011

[15] Baiocchi, G. and Rocha, R.M. (2014) Vulvar Cancer Surgery. Current Opinion in Obstetrics \& Gynecology, 26, 9-17. http://dx.doi.org/10.1097/GCO.0000000000000033

[16] Mitchell, S.A., Beck, S.L., Hood, L.E., Moore, K. and Tanner, E.R. (2007) Putting Evidence into Practice: EvidenceBased Interventions for Fatigue during and Following Cancer and Its Treatment. Clinical Journal of Oncology Nursing, 11, 99-113. http://dx.doi.org/10.1188/07.CJON.99-113

[17] Poage, E., Singer, M., Armer, J., Poundall, M. and Shellabarger, M.J. (2008) Demystifying Lymphedema: Development of the Lymphedema Putting Evidence into Practice Card. Clinical Journal of Oncology Nursing, 12, 951-964. http://dx.doi.org/10.1188/08.CJON.951-964

[18] Polit, D.F. and Beck, C.T. (2013) Essentials of Nursing Research. Appraising Evidence for Nursing Practice. 8th Edition, Wolters Kluwer Health /Lippincott Williams \& Wilkins, Philadelphia.

[19] Mitchell, H.K. (2010) Evaluating Clinical and Public Health Interventions. A Practical Guide to Study Design and Statistics. Cambridge University Press, Cambridge.

[20] Stringer, E.T. (2004) Action Research in Education. 2nd Edition, Pearson Prentice Hall, Upper Saddle River.

[21] Baartmans, P.C.M. and Geng, V. (2006) Qualität nach Maß. Entwicklung und Implementierung von Qualitätsverbesserungen im Gesundheitswesen. 2., vollst. überarb. und erw. Aufl. Huber (Pflegemanagement), Bern.

[22] Swiss Academy of Medical Sciences (SAMW) (2009) Forschung mit Mensch: Ein Leitfaden für die Praxis. http://www.samw.ch/dms/de/Projekte/Forschung-mit-Menschen/d_Leitfaden_Forschung/LeitfForschMensch_Web_Nov09.pdf 
[23] Mayring, P. (2008) Qualitative Inhaltsanalyse. Grundlagen und Techniken. 11., aktualisierte und überarb. Aufl. Beltz (Studium Paedagogik), Weinheim.

[24] Bortz, J. and Döring, N. (2006) Forschungsmethoden und Evaluation. Für Human- und Sozialwissenschaftler; mit 87 Tabellen. 4., überarb. Aufl., [Nachdr.]. Springer-Lehrbuch Bachelor, Master, Springer-Medizin-Verl, Heidelberg. http://dx.doi.org/10.1007/978-3-540-33306-7

[25] Grønkjær, M., Eliasen, M., Skov-Ettrup, L.S., Tolstrup, J.S., Christiansen, A.H. and Mikkelsen, S.S. (2014) Preoperative Smoking Status and Postoperative Complications: A Systematic Review and Meta-Analysis. Annals of Surgery, 259, 52-71. http://dx.doi.org/10.1097/SLA.0b013e3182911913

[26] Sørensen, L.T. (2012) Wound Healing and Infection in Surgery. The Clinical Impact of Smoking and Smoking Cessation: A Systematic Review and Meta-Analysis. Archives of Surgery, 147, 373-383.

[27] Thomsen, T., Villebro, N. and Møller, A.M. (2010) Interventions for Preoperative Smoking Cessation. The Cochrane Database of Systematic Reviews, 7, CD002294. http://dx.doi.org/10.1002/14651858.cd002294.pub3

[28] Oppedal, K., Møller, A.M., Pedersen, B. and Tønnesen, H. (2012) Preoperative Alcohol Cessation Prior to Elective Surgery. The Cochrane Database of Systematic Reviews, 7, CD008343. http://dx.doi.org/10.1002/14651858.cd008343.pub2

[29] Nickelsen, T.N., Jørgensen, T. and Kronborg, O. (2005) Lifestyle and 30-Day Complications to Surgery for Colorectal Cancer. Acta Oncologica, 44, 218-223. http://dx.doi.org/10.1080/02841860510029707

[30] Artioukh, D.Y., Smith, R.A. and Gokul, K. (2007) Risk Factors for Impaired Healing of the Perineal Wound after Abdominoperineal Resection of Rectum for Carcinoma. Colorectal Disease, 9, 362-367. http://dx.doi.org/10.1111/j.1463-1318.2006.01159.x

[31] Gottrup, F., Melling, A. and Hollander, D.A. (2005) An Overview of Surgical Site Infections: Aetiology, Incidence and Risk Factors. EWMA Journal, 5, 11-15.

[32] Senn, B., Gafner, D., Raphaelis, S., Meyer, G., Mayer, H. and White, K. (2013) Testing the Counsellig Program "WOMAN-PRO II": An International Multicenter Mixed-Methods Study Protocol. Poster Presentation. 18th International Meeting of the European Society of Gynecological Oncology, Liverpool, 19-22 October 2013.

[33] Maier, S., Körner, P., Diedrich, S., Kramer, A. and Heidecke, C-D (2011) Definition und Management der Wundinfektion. Der Chirurg, 82, 235-241. http://dx.doi.org/10.1007/s00104-010-2012-5

[34] Senn, B., Mueller, M.D., Cignacco, E.L. and Eicher, M. (2010) Period Prevalence and Risk Factors for Postoperative Short-Term Wound Complications in Vulvar Cancer: A Cross-Sectional Study. International Journal of Gynecological Cancer, 20, 646-654. http://dx.doi.org/10.1111/IGC.0b013e3181d92723

[35] Beesley, V., Janda, M., Eakin, E., Obermair, A. and Battistutta, D. (2007) Lymphedema after Gynecological Cancer Treatment. Prevalence, Correlates, and Supportive Care Needs. Cancer, 109, 2607-2614. http://dx.doi.org/10.1002/cncr.22684

[36] de Hullu, J.A., van der Avoort, I.A.M., Oonk, M.H.M. and van der Zee, A.G.J. (2006) Management of Vulvar Cancers. European Journal of Surgical Oncology, 32, 825-831. http://dx.doi.org/10.1016/j.ejso.2006.03.035

[37] Royal College of Obstetricians and Gynaecologist (2006) Guidelines for the Diagnosis and Management of Vulval Carcinoma. https://www.rcog.org.uk/globalassets/documents/guidelines/vulvalcancerguideline.pdf

[38] Green, M.S., Naumann, R.W., Elliot, M., Hall, J.B., Higgins, R.V. and Grigsby, J.H. (2000) Sexual Dysfunction Following Vulvectomy. Gynecologic Oncology, 77, 37-77. http://dx.doi.org/10.1006/gyno.2000.5745

[39] Thuesen, B., Andreasson, B. and Bock, J.E. (1992) Sexual Function and Somatopsychic Reactions after Local Excision of Vulvar Intra-Epithelial Neoplasia. Acta Obstetricia et Gynecologica Scandinavica, 71, 126-128. http://dx.doi.org/10.3109/00016349209007969

[40] Likes, W.M., Russell, C. and Tillmanns, T. (2008) Women’s Experiences with Vulvar Intraepithelial Neoplasia. Journal of Obstetric, Gynecologic, and Neonatal Nursing, 37, 640-646. http://dx.doi.org/10.1111/j.1552-6909.2008.00291.x

[41] Patrick, D.L., Ferketich, S.L., Frame, P.S., Harris, J.J., Hendricks, C.B. and Levin, B. (2003) National Institutes of Health State-of-the-Science Conference Statement: Symptom Management in Cancer: Pain, Depression, and Fatigue, July 15-17, 2002. Journal of the National Cancer Institute, 95, 1110-1117. http://dx.doi.org/10.1093/jnci/djg014

[42] Bundesamt für Gesundheit, Schweizerische Gesundheitsdirektorenkonferenz (2011) Nationales Krebsprogramm für die Schweiz 2011-2015. http://www.oncosuisse.ch/file/oncosuisse/nkp/2011-2015/vollversion/NKP Vollversion d.pdf

[43] Basch, E., Jia, X., Heller, G., Barz, A., Sit, L. and Fruscione, M. (2009) Adverse Symptom Event Reporting by Patient's vs Clinicians: Relationships with Clinical Outcomes. Journal of the National Cancer Institute, 101, 1624-1632. http://dx.doi.org/10.1093/jnci/djp386

[44] McNees, P. (2006) Skin and Wound Assessment and Care in Oncology. Seminars in Oncology Nursing, 22, $130-143$. 
http://dx.doi.org/10.1016/j.soncn.2006.04.003

[45] Mitic, W., Ben Abdelaziz, F. and Madi, H. (2012) Health Education. Theoretical Concepts, Effective Strategies and Core Competencies. World Health Organization, Regional Office for the Eastern Mediterranean, Cairo. http://applications.emro.who.int/dsaf/EMRPUB_2012_EN_1362.pdf

[46] Leminen, A., Forss, M. and Paavonen, J. (2000) Wound Complications in Patients with Carcinoma of the Vulva. European Journal of Obstetrics \& Gynecology and Reproductive Biology, 93, 193-197. http://dx.doi.org/10.1016/S0301-2115(00)00273-6

[47] Rouzier, R., Haddad, B., Dubernard, G., Dubois, P. and Paniel, B.-J. (2003) Inguinofemoral Dissection for Carcinoma of the Vulva. Effect of Modifications of Extent and Technique on Morbidity and Survival. Journal of the American College of Surgeons, 196, 442-450. http://dx.doi.org/10.1016/S1072-7515(02)01895-1

[48] Uyl-De Groot, C.A., Hartog, J.G.-D., Derksen, J.G.M., Symons, E.A., Buijt, I., van der Velden, J. and van Lindert, A.C.M. (2004) Cost-Effectiveness and Quality of Life of Granulocyte-Colony Stimulating Factor (Filgrastim) after Radical Vulvectomy and Bilateral Inguino-Femoral Lymphadenectomy: Results of a Randomized Clinical Trial. European Journal of Obstetrics, Gynecology, and Reproductive Biology, 114, 77-82. http://dx.doi.org/10.1016/j.ejogrb.2003.09.018

[49] Van der Zee, A.G.J., Oonk, M.H., de Hullu, J.A., Ansink, A.C., Vergote, I. and Verheijen, R.H. (2008) Sentinel Node Dissection Is Safe in the Treatment of Early-Stage Vulvar Cancer. Journal of Clinical Oncology, 26, 884-889. http://dx.doi.org/10.1200/JCO.2007.14.0566

[50] Andersen, B.L. and Hacker, N.F. (1983) Psychosexual Adjustment after Vulvar Surgery. Obstetrics and Gynecology, 62, 457-462.

[51] Janda, M., Obermair, A., Cella, D., Crandon, A.J. and Trimmel, M. (2004) Vulvar Cancer Patients' Quality of Life: A Qualitative Assessment. International Journal of Gynecological Cancer, 14, 875-881. http://dx.doi.org/10.1111/j.1048-891X.2004.14524.X

[52] Harbour, R. and Miller, J. (2001) A New System for Grading Recommendations in Evidence Based Guidelines. BMJ, 323, 334-336. http://dx.doi.org/10.1136/bmj.323.7308.334

[53] Mead, P. (2000) Clinical Guidelines: Promoting Clinical Effectiveness or a Professional Minefield? Journal of Advanced Nursing, 31, 110-116. http://dx.doi.org/10.1046/j.1365-2648.2000.01254.x 